\title{
Solution Focused Brief Therapy Applied to Diverse Classroom Settings in a Four-Year University
}

\author{
Charity Perry \\ Department of Sociology, California State University, Los Angeles, USA \\ Email: cperry5@calstatela.edu
}

Received 3 September 2014; revised 5 October 2014; accepted 19 October 2014

Copyright (C) 2014 by author and Scientific Research Publishing Inc.

This work is licensed under the Creative Commons Attribution International License (CC BY). http://creativecommons.org/licenses/by/4.0/

\section{(c) (i) Open Access}

\begin{abstract}
Solution Focused Brief Therapy was developed during the late 1970s and 1980s by Steve de Shazer and his colleagues. The purpose of this paper was to examine the application of Solution Focused Brief Therapy's parallels with the author's classroom experiences in a higher education setting that gave special considerations to the author's disciplines of sociology, critical thinking, and marriage and family therapy. More specifically, the unique experiences are brought to a classroom by students much in the same manner that individuals bring experiences to a therapist who practices Solution Focused Brief Therapy. The author concludes that the perception of what constitutes a problem can be expressed as a limitation, not just merely defined as a problem.
\end{abstract}

\section{Keywords}

Solution Focused Brief Therapy, Creative Education, Higher Education, Diversity, Perception

\section{Brief Overview of Solution Focused Brief Therapy}

Solution Focused Brief Therapy, hereafter referred to as SFBT, was influential based on past developments by efforts of the Mental Research Institute (MRI) in Palo Alto, California. The work at the MRI was influenced by Milton Erickson, a world-renowned psychiatrist, psychologist, and hypnotherapist. His work pointed toward principles of a solution-focused approach (Visser, 2013). Gregory Bateson was also influential in the initial efforts of solution focused therapy. Bateson’s work focused on cybernetics and systems theory (Bateson, 1972). Bateson contributed to two fundamental principles of SFBT. First, he posits that individuals social system in which they function gives insight into the development of problems and solutions, and idea which we can attach to one's individual culture; and secondly, his greatest contribution was The Bateson Project (Cade, 2007) thereby, 
making the work of therapy pioneers such as John Weakland, Jay Haley, and others (Visser, 2013) more available to the public. The fundamental differs in SFBT and the MRI approach concerns emphases given by each concept of the "solution". The MRI approach seeks to interdict existing solutions that maintain the problem and promote "less of the same". SFBT seeks to develop new solutions after identifying exception to the problems discussed by one's client. The Brief Family Therapy Center was established by Steve de Shazer and Insoo Kim Berg in 1978 and focused on what worked in therapy, building theories around "accidents" in therapeutic conversations rather than analysis and diagnoses that came from typical client interactions in a therapy session. The focus then became on interventions for clients which established goal-oriented outcomes thereby creating a more optimistic outlook for their clients.

Considering the submerged competencies of clients, not only are problems defined and re-defined by the therapist, but it is important to consider what actually defines a "problem" as they are suggested by the SFBT model and the problems or attempts to solve the problems focused upon this theoretical model. SFBT is also described as a process oriented, non-linear approach in marriage and family therapy; SFBT is solution-building rather than problem-solving (Iveson, 2002). After eight successful years, a firm foundation was laid for global undertaking in therapy.

\section{Exploring the Process of Process}

Application of this framework by the researcher to existing knowledge of sociological theory, critical thinking, and family systems led to the question: Can process be seen as a problem?

Teaching students with diverse cultural backgrounds at a four-year institution, while weighing sociological aspects and family systems thinking toward problem solving is a strategic task. Determining whether or not a problem is a problem requires objective thought. At times, an initial response of student's peers is a dance of downplaying one's presented "problems". In fostering an atmosphere of critical thinking, allowing a student to verbalize thoughts on without interruption is often the greatest task. The introduction of students into understanding personal biases and prejudices via a discussion of their individuality and belief systems (which is largely based upon their authority figures at this point in their lives) is crucial to understanding the voice of their peers and reflecting on "where someone is coming from". Chris Iveson (2002) notes four key tasks of therapists during the first session: find out what the person is hoping to achieve from the meeting or working together; find out what the small, mundane and details of the person's life would be like if these hopes were realized; find out what the person has done in the past or is doing in the future that may contribute to the hopes being realized; and find out what could possibly be different if one makes the steps necessary in realizing the hopes presented to the therapist. The current researcher's thoughts parallel previous researchers who determined the idea of meeting a client "where they are at" is reminiscent of the scenario encountered on a daily basis with students in the classroom that is representative in many diverse backgrounds of students.

During the initial meeting phase of a client and therapist, precedence is given to clients by accepting the version of a clients' story that is presented by the client as real and valid (Smock et al., 2008). There is a parallel approach to SFBT while teaching such classes in sociology, and critical thinking; and certainly, other disciplines. We have to first understand that stereotypes exist, and are reinforced every day, yet an educator must take it on faith that a student is being honest about their individual circumstances. Meeting students "where they are at" usually involves a strategic dance which is discussed in more detail below.

Allowing such interactions and fostering a non-judgmental atmosphere is crucial from the first moments of the encounter between a student and educator to the last steps of giving a final exam. If a platform (interchanged with a stage, or voice) is given to a student knowing the educator only has a brief amount of "sessions" with them, it is imperative that we work through the "process" of problem solving based on respectfully taking into account the life experience of the student. Creating a safe classroom environment in which one can develop the ability to go beyond the stereotypes and see that not everyone "fits the mold perfectly" parallels a SFBT therapist, who must "think on their feet", especially given the limited number of sessions spent with the client.

Giving a nod to our individual cultures and backgrounds can mirror the safe environment created by a therapist, that as educators, we strive to attain. Establishing a safe environment for a student muck like the safe environment created by a therapist in which the therapist takes the clients truths as their reality and based on that reality, a sense of acceptance is created, therefore allowing an opportunity for the client to express that which is essential to introducing tools in which to explore problems based on "where the client is at". Behaviors based on 
psychological, physical, and emotional characteristics of clients/students in the initial meeting posits that taking all of these perspectives into account help to gain a greater understanding of a client/student and how to create a platform in which solutions to a problem(s) can be determined.

Fostering growth in numerous individuals contextually requires dedication and goal setting. Educators often set goals for their classrooms before ever meeting their students. SFBT seems to parallel this dedication in that it has a specific purpose and short term goals. Student in parallel to SFBT must meet their short term goals (a successful experience, grade) in an educator's class to be successful in their long term goals (graduating from college). SFBT is designed as a platform which centers on the concerns of a client, much like those of a student, visions of what their futures will be (their hopes and dreams), the strengths and resources which are usually directed toward the future vision; and how to set goals so they can re-evaluated the progress being made toward the goals by having assignments to account for the solution, through re-evaluating the progress being made toward the ultimate short term goal (passing the class), the educator monitors the class by giving grades and feedback.

Second, as previously indicated, evaluating one's belief system becomes critical by introducing means in which to validate these systems, or help with a co-construction of altered or altogether new belief system. At times, college students find themselves questioning their belief systems yet not wanting to admit to anyone they are being challenged. Students may believe they are changing, which some therapists view as differentiation of self (which tends to occur during major life events, such as moving away to college, this particular age group being 20 - 25 years old).

Having a classroom atmosphere where topics are open to discussion (i.e., racial stereotypes, cultural stereotypes) fosters expression and realization that these events have been reinforced every day in some way or another for the student. Specific techniques used by the author of this paper such as in-class groups helps to target specific responses which result in a building block of solutions and fosters growth by questioning the perspectives of others (without judging) to gain a greater perspective on where another individual is coming from.

SFBT therapists invite their clients along in constructing a vision that draws on past successes, strengths and resources to make the visions a reality. As an educator/professor, the current researcher is hopeful this occurs in her classroom during the brief time she has with students so they ultimately can identify with their cultures, draw experience from life experiences they have had thus far, and create a platform in which their visions can become a reality. This technique tends to mirror the goal setting which in an important concept in SFBT. SFBT has been targeted by previous researchers (Newsome, 2004) who focused on group work with an at-risk junior high school student group and compared two separate groups of 26 students. The research showed that the students who were in the treatment group that modeled SFBT increased their grade point average when compared to the group who did not follow the model.

\section{Process as a Problem}

There are limitations in some processes. Limitations differ in meaning from therapist/educator. Some limitations are viewed as problems and some limitations are viewed as exceptions. Potential limitations that the author experiences with respect to the parallel in SFBT, is the concept of a limited number of sessions (15 - 18 as an average). The author's classroom time with students can be considered brief, compared to instruction received from institutions, which may utilize a semester system (approximately 28 sessions on average). Educators have a limited number of sessions in which to set goals, understanding the individual needs that are presented with the uniqueness of each class and the students in the classroom, and creating insight for the students to help discover the obstacles they already have to meet their goals. Due to the short duration of SFBT (i.e., 5 - 12 sessions usually) there are a number of scales (Iveson, 2002) used in identifying the specific framework that a therapist may pursue in this approach. The current author uses sociological concepts, family systems thinking and critical thinking. The parallel of SFBT applied to the experience of the author in that there are a set number of "sessions" in which a therapist/educator can explore solutions based on where a client/student is.

At times, this "process" can lead to other problems, exceptions, or limitation such as a defense by the student discussing their "problem" with their in class groups (usually 5 people) to determine whether the problem presented actually meets certain criteria is often subjective based upon an individual's influences of the culture and the society in which they are a part of. 


\section{Process as Therapy}

The idea of process as therapy helps the author's students to grow from the first day they step into the classroom until the last day they have together. The process of content mastery along with the application of the content is crucial to the success of the student. SFBT parallels this by therapist's recognition of what tools the client has brought with them and how the tools will be used to meet client's needs. Through the idea of changing, yet recognizing the student's exceptions (i.e., belief systems, cultural differences) the process as therapy is beneficial. The classroom environment has guidelines that must be adhered to by the students (i.e., syllabus, discussions, classroom expectations, what they can expect to encounter, what they can count on from the educator). The author is optimistic the student will take away a hopeful expectation and tools which can be applied to other areas of their lives which are influenced by their various roles within society (i.e., work, relationships, family).

\section{Conclusion}

The purpose of this paper was to examine the applications of Solution Focused Brief Therapy's parallels with the author's classroom experiences in a higher education setting that gave special considerations to the authors' disciplines of sociology, critical thinking, and marriage and family therapy. In examining the parallels of SFBT and applying the knowledge of this particular approach in therapy, we can determine that seeing process as a problem, solution or therapy can be ambiguous, yet the model is applicable to a variety of contexts. In an examination of previous research that was compared in this paper, and application of personal classroom experience, the current author supports De Shazer (1994) that SFBT is an evolving model. It seems the freedom to explore other avenues in which the model can be applied is welcomed and encouraged. Through the exploration of SFBT as a model for classroom change, continued efforts in a classroom modeled by students and the educator with creative freedom an educator can apply in a classroom, the more platforms for change can be created. The question posed earlier in this paper is: Can process be seen as a problem? The author concludes that the perception of what constitutes a problem can be expressed as a limitation, not just merely defined as a problem.

\section{References}

Bateson, G. (1972). Steps to an Ecology of Mind: Collected Essays in Anthropology, Psychiatry, Evolution, and Epistemology. Chicago, IL: University of Chicago Press.

Berg, I. K. (1996). Solution-Building Conversations: Co-Constructing a Sense of Competence with Clients. Families in Society, 77, 376-391. http://dx.doi.org/10.1606/1044-3894.934

Cade, B. (2007). Springs, Streams, and Tributaries: A History of the Brief, Solution-Focused Approach. In T. Nelson \& F. Thomas (Eds.), Handbook of Solution-Focused Brief Therapy.

De Shazer, S. (1994). Words Were Originally Magic. New York: Norton.

Berg, I. K., Lipchik, E., Nunnally, E., Molnar, A. Gingerich, W., Weiner-Davis, M. et al. (1986). Brief Therapy: Focused Solution Development. Family Process, 25, 207-221. http://dx.doi.org/10.1111/j.1545-5300.1986.00207.x

Iveson, C. (2002). Solution-Focused Brief Therapy. Journal of Continuing Professional Development, 8, 149-156.

Newsome, W. S. (2004). Solution-Focused Brief Therapy Groupwork with At-Risk Junior High School Students: Enhancing the Bottom Line. Research on Social Work Practice, 14, 336-343. http://dx.doi.org/10.1177/1049731503262134

Smock, S., Trepper, T., Wetchler, J., McCollum, E., Ray, R., \& Pierce, K. (2008). Solution Focused Group Therapy for Level 1 Substance Abusers. Journal of Marital and Family Therapy, 34, 107-120.

http://dx.doi.org/10.1111/j.1752-0606.2008.00056.x

Visser, C. F. (2013). The Origin of Solution-Focused Approach. International Journal of Solution-Focused Practice, 1, 1017. http://dx.doi.org/10.14335/ijsfp.v1i1.10 
Scientific Research Publishing (SCIRP) is one of the largest Open Access journal publishers. It is currently publishing more than 200 open access, online, peer-reviewed journals covering a wide range of academic disciplines. SCIRP serves the worldwide academic communities and contributes to the progress and application of science with its publication.

Other selected journals from SCIRP are listed as below. Submit your manuscript to us via either submit@scirp.org or Online Submission Portal.
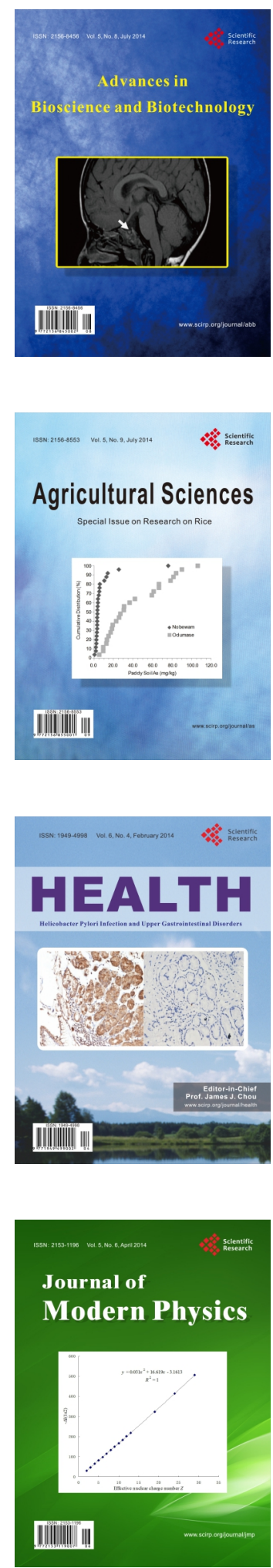
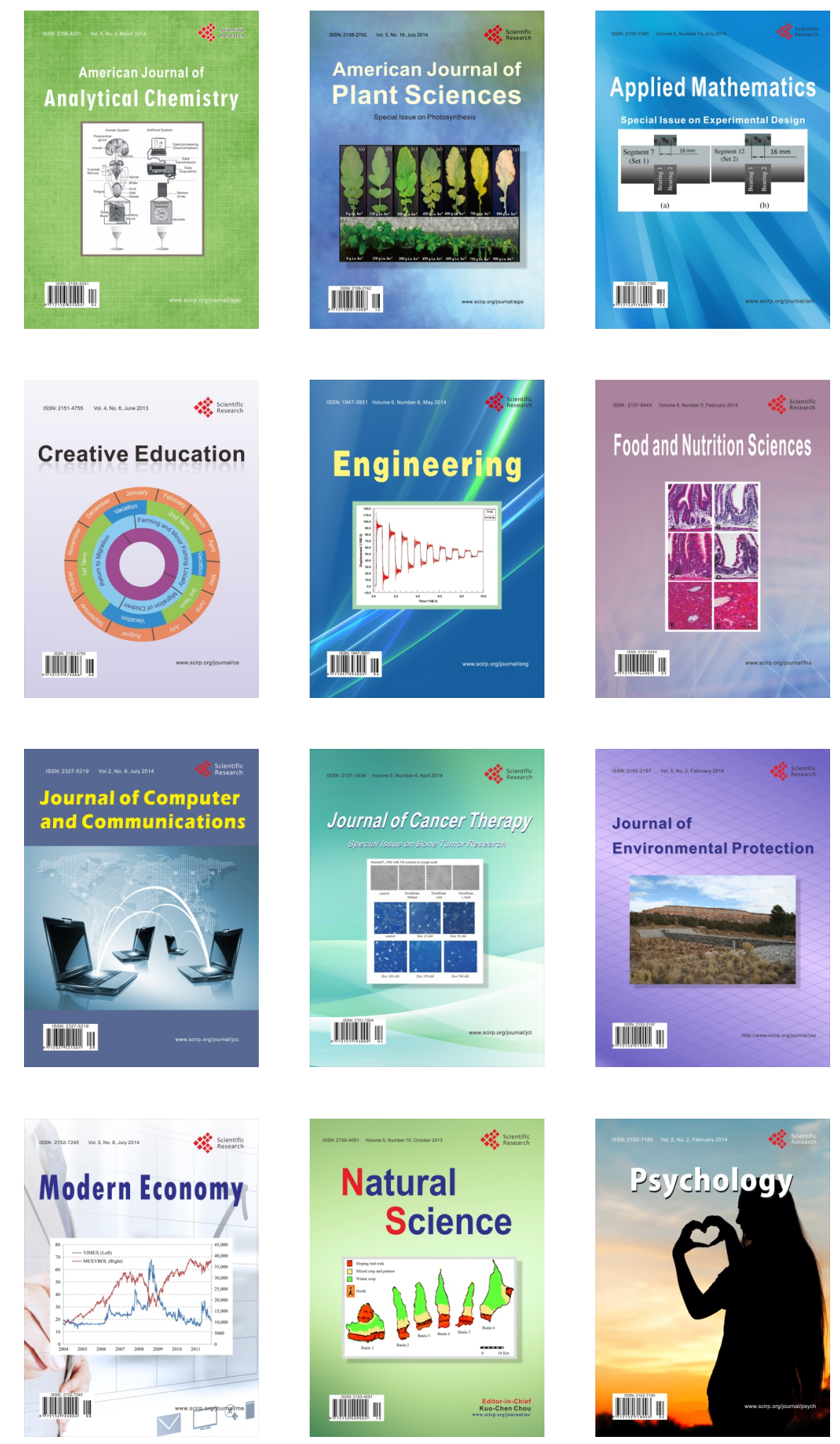